\title{
Thyroid papillary carcinoma presenting with femoral neck metastasis: a case report
}

\author{
Birol Aktas ${ }^{1}$, Mehmet Esat Uygur ${ }^{2}$, Mehmet Salih Soylemez ${ }^{3}$, Bahattin Kemah ${ }^{1}$, \\ Bilge Bilgic $^{4}$, Bahar Ceyran ${ }^{5}$, Korhan Ozkan ${ }^{1}$
}

\author{
${ }^{1}$ Department of Orthopaedics and Traumatology, ${ }^{5}$ Department of Pathology, Goztepe Training and Research Hospital, \\ Istanbul Medeniyet University, Istanbul, Turkey \\ ${ }^{2}$ Department of Orthopaedics and Traumatology, Emsey Hospital, Istanbul, Turkey \\ ${ }^{3}$ Department of Orthopaedics and Traumatology, Bingol State Hospital, Bingol, Turkey \\ ${ }^{4}$ Department of Pathology, Istanbul University, Faculty of Medicine, Istanbul, Turkey
}

Received: 19 July 2016

Accepted: 11 August 2016

*Correspondence:

Dr. Mehmet Salih Soylemez,

E-mail: slhsylmz@gmail.com

Copyright: (c) the author(s), publisher and licensee Medip Academy. This is an open-access article distributed under the terms of the Creative Commons Attribution Non-Commercial License, which permits unrestricted non-commercial use, distribution, and reproduction in any medium, provided the original work is properly cited.

\begin{abstract}
Thyroid carcinoma is relatively uncommon, accounting for $2 \%$ of all cancers. Although they usually present as a neck lump, occasionally they may be presented with a distant metastasis. In this study, a 65 year-old woman was referred to our clinic with a pain on her left hip at both rest and walking. A lytic area at the inferior femoral neck was found with plain radiography. To clarify the characteristics of the lesion, left hip magnetic resonance imaging (MRI) had been performed displaying $3 \times 5 \mathrm{~cm}$ hyperintense lesion extending from medial part of the left femoral neck to the left femoral head. Laboratory findings were normal. An open biopsy had then been performed from the left femoral neck with a suspicion of a metastatic tumor. After Immunohistochemical assesment diagnosis was consistent with metastatic thyroid papillary cancer. Proximal femoral resection with clear margins were achieved by proximal femur tumor endoprosthesis. In conclusion, papillary thyroid cancer have an excellent prognosis and doesn't tend to metastese. But rarely, as seen in our case it can even present with syptoms of metastasic disease. Management strategy is the same as other solitary bone metastasis. Papillary thyroid cancer must be kept in mind as a differential diagnosis in solitary bone metatasis.
\end{abstract}

Keywords: Papillary thyroid carcinoma, Bone metastasis, Solitary bone lesion

\section{INTRODUCTION}

Thyroid carcinoma is relatively uncommon, accounting for $2 \%$ of all cancers. ${ }^{1}$ Papillary thyroid carcinoma is one of the well-differentiated tumor subtypes, composing of $80 \%$ of all thyroid cancers. They generally have high survival rates; solitary distant metastases are extremely rare. Thyroid cancers can metastasize to different parts of the body, especially to the lungs and bones. In patients with metastatic thyroid cancers, diagnosis is usually delayed due to an unclear nature of the symptoms while the metastases continue to decrease the quality of life and survival time.
Herein we report a case suffering from hip pain for a long time. Patient was diagnosed as papillary carcinoma metastasis after biopsy from the femoral neck. We aimed to discuss papillary thyroid carcinoma, with an initial discussion about the metastases to the femoral neck and emphasis on the importance of differential diagnosis.

\section{CASE REPORT}

A 65 year-old woman was referred to our clinic with pain in her left hip, while resting or walking. Her past history revealed no chronic diseases. In her physical examination she had intense pain during flexion-internal rotation on 
her left hip. A lytic area at the inferior femoral neck was found with plain radiography as shown in Figure 1A. To clarify, the characteristics of the lesion had been performed with a magnetic resonance imaging (MRI) on her left hip. The MRI showed a $3 \times 5 \mathrm{~cm}$ hyperintense lesion extending from the medial part of the left femural neck to the left femural head on T2 sequence as given in Figure 1B. Preoperatively, a computerized tomography (CT) scan of the chest, abdomen and pelvis was made to detect any possible primary tumor origin. In addition, breast ultrasonography and mammography, protein electrophoresis and gastrointestinal tumor markers were ordered. All these investigations did not detect any abnormalities.
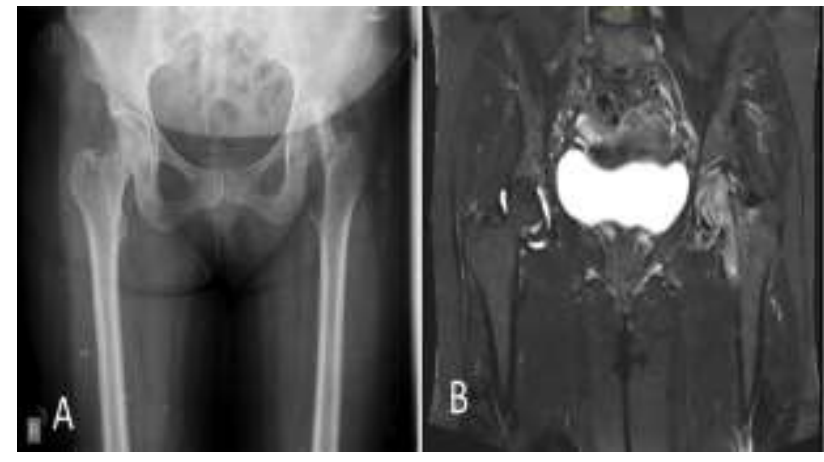

Figure 1A: Anteroposterior pelvis X-ray showing a lytic lesion in the inferior part of left femur neck. 1B:

Pelvic MRI showing $3 \times 5 \mathrm{~cm}$ hyperintense lesion extending from medial part of left femur neck to the left femur head on $\mathrm{T} 2$ sequence.

An open biopsy had also been performed from the left femoral neck. Immunohistochemical stains, including thyroid transcription factor 1 as seen in Figure $2 \mathrm{~A}$, mesotelioma antibody (HBME-1) as in Figure 2B, thyroglobulin, and pancytokeratin antibodies were all positive and the diagnosis was consistent with follicular variant of metastatic thyroid papillary cancer. The technetium-99 total body bone scan did not detect any other bone involvement. Thyroid ultrasonography and positron emission tomography (PET/CT) were performed for further evaluation.

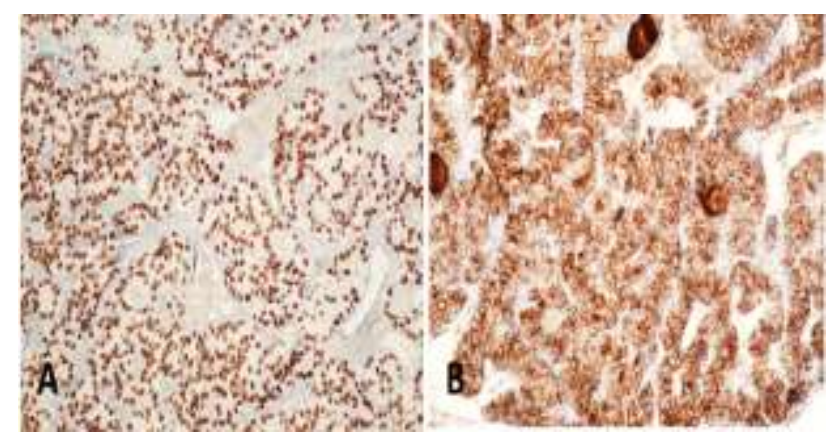

Figure 2A: Microscopic images showing immunohistochemistry; positive staining for thyroid transcription factor- 1 (TTF-1, 200X) and 2B: Positive staining for mesotelioma antibody (HBME-1, 200X).
In her ultrasonographic examination of the thyroid gland, an increased thyroid parenchymal echogenicity and heterogenity were determined. Multiple nodules, macro and micro-calcifications, and cystic-solid areas were seen throughout the thyroid gland which had also increased in size.

A positron emission tomography with 2-deoxy-2[fluorine-18]fluoro- D-glucose integrated with computed tomography $\left({ }^{18} \mathrm{~F}-\mathrm{FDG}\right.$ PET/CT) evaluation displayed a focally-increased uptake in the right jugular, as well as in the right infraclavicular lymph nodes. A slightly increased metabolic activity was also found in the subplevral nodule near the middle lobe lateral segment of the right lung. Malignant hypermetabolic nodules were found in both thyroid glands. Consulting with the oncology department, it was first decided to operate on the solitary bone metastasis to prevent a possible pathological fracture.

Proximal femoral resection with clear margins were achieved using lateral incision, followed by the use of proximal femur tumor endoprosthesis (Penta, TIPSAN; Turkey) as given in Figure 3. The patient was hospitalized for five days in which any complications would have been detected after surgery; however, there were no issues that arose. The patient was then referred to both the oncology and the head-neck surgery departments for further evaluation and treatment.

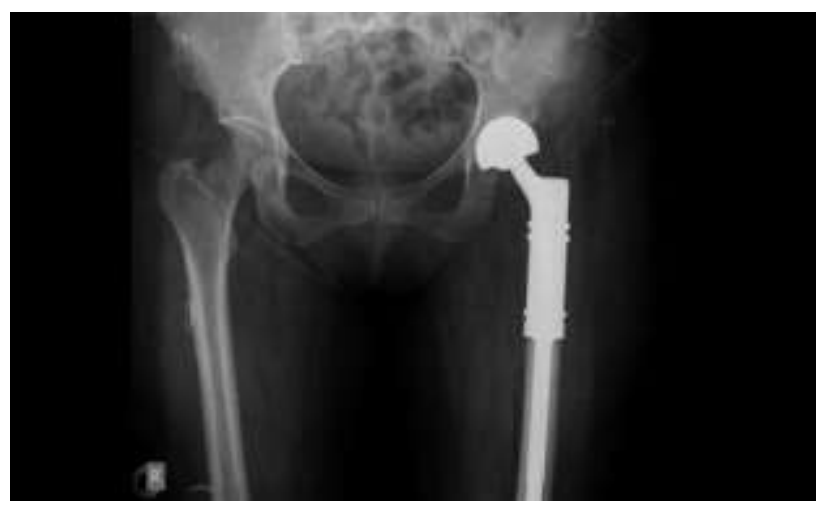

Figure 3: Anteroposterior pelvis X-ray showing the treatment by using proximal femoral tumor endoprosthesis (Penta, TIPSAN; Turkey).

\section{DISCUSSION}

Generally, thyroid cancers have a low mortality rate with a high survival rate. Eighty-five to 90 percent of all thyroid cancers are well-differentiated types, including: papillary, follicular and Hurtle cell carcinoma. ${ }^{1}$ The less common thyroid cancers with poorer prognoses include medullary, anaplastic, lymphoma and metastatic diseases. ${ }^{1}$ The metastatic thyroid carcinoma group includes those with distant metastases at initial presentation and those with metastases occurring after treatment. $^{2,3}$ This group constitutes less than $10 \%$ of thyroid cancers, and unfortunately causes the most 
common thyroid cancer-related deaths. Only one to three percent of patients with thyroid cancer are detected with distant metastasis at the time of diagnosis. ${ }^{3}$

The clinical evaluation of a patient aged $>40$ years who presents with a destructive bone lesion includes a careful history, physical examination, imaging workup, biopsy strategy, and final staging. The differential diagnosis includes metastatic bone disease, multiple myeloma, lymphoma, primary malignant bone tumor, destructive benign bone lesion, and nonneoplastic conditions. ${ }^{4}$

Usually thyroid carcinoma presents itself as a lump in the neck. Solitary bone metastasis leading to a diagnosis of thyroid carcinoma, especially the papillary type, is extremely rare. Unlike the good prognosis of papillary cancer confined to thyroid glands or cervical lymph nodes, distant metastasis increases mortality up to $50 \%$ in a year. ${ }^{5,6}$ Comparatively, metastasis in the lungs are worse than metastases among bones. ${ }^{7}$ Patients with initial distant metastases, compared to those who developed distant metastasis after initial presentation, have a better rate of survival. Additionally, the age at the diagnosis (being older than 60 years of age), type of histology (papillary is better than follicular), and having no iodineavidity are directly proportional to the risk of recurrence and death. Surgical removal of the solitary metastases of thyroid cancers is recommended for improved survival and quality of life. ${ }^{8,11}$

To detect the possible primary origin of the metastatic lesion, conventional diagnostic evaluation techniques might be insufficient. To detect the lesions, the highly sensitive 18F-fluoro-2-deoxyglucose positron emission tomography (FDG PET)/ computed tomography (CT) may be used to find the primary focus. ${ }^{9,10}$

As a conclusion; medullary, anaplastic and poorly differentiated thyroid cancers tend to metastase to bones. Howevere papillary thyroid cancer have an excellent prognosis and doesn't tend to metastese. But rarely, as seen in our case it can even present with syptoms of metastasic disease. Management strategy is the same as other solitary bone metastases. Papillary thyroid cancer must be kept in mind as a differential diagnosis in solitary bone metatases.

Funding: No funding sources Conflict of interest: None declared

Ethical approval: Not required

\section{REFERENCES}

1. Lai S, Susan Y, Mandel J, Weber RS. Disorders of the Thyroid Gland. In: Cummings CW, Haughey
BH, Thomas JR, Harker LA, Robins K, Flint PW, Schuller D, Cummings R, editors, Otolaryngology: Head and Neck Surgery. Inc:Philadelphia, PA Mosby Pub; 2005: 1735-1750.

2. Shoup M, Stojadinovic A, Nissan A, Ghossein RA, Freedman S, Brennan MF, et al. Prognostic indicators of outcomes in patients with distant metastases from differentiated thyroid carcinoma. J Am Coll Surg. 2003;197(2):191-7.

3. Durante C, Haddy N, Baudin E, Leboulleux S, Hartl D, Travagli JP, et al. Long-term outcome of 444 patients with distant metastases from papillary and follicular thyroid carcinoma:benefits and limits of radioiodine therapy. J Clin Endocrinol Metab. 2006;91(8):2892-9.

4. Weber KL. Evaluation of the adult patient (aged> 40 years) with a destructive bone lesion. J Am Acad Orthop Surg. 2010;18(3):169-79.

5. Gimm O, Dralle H. Differentiated thyroid carcinoma. In: Holzheimer RG, Mannick JA editors. Surgical Treatment: Evidence-Based and ProblemOriented, W. Zuckschwerdt Verlag Munchen; 2001.

6. Wu K, Hou SM, Huang TS, Yang RS. Thyroid carcinoma with bone metastases: a prognostic factor study. Clin Med Oncol. 2008;2:129-34.

7. Hindié E, Zanotti-Fregonara P, Keller I, Duron F, Devaux JY, Calzada-Nocaudie $\mathrm{M}$, et al. Bone metastases of differentiated thyroid cancer: impact of early 131I-based detection on outcome. Endocrine-Related Cancer. 2007;14:799-807.

8. Perros P, Boelaert K, Colley S, Evans C, Evans RM, Gerrard Ba G, et al. Guidelines for the management of thyroid cancer. Clinical endocrinology. 2014;81(1):1-122.

9. Kwee TC, Kwee RM. Combined FDG-PET/CT for the detection of unknown primary tumors: systematic review and meta-analysis. European radiology. 2009;19(3):731-44.

10. Mazzaferri EL, Robbins RJ, Spencer CA, Braverman LE, Pacini F, Wartofsky L, et al. A consensus report of the role of serum thyroglobulin as a monitoring method for low-risk patients with papillary thyroid carcinoma. The Journal of Clinical Endocrinology \& Metabolism. 2003;88(4):1433-41.

11. Kwee TC, Basu S, Cheng G, Alavi A. FDG PET/CT in carcinoma of unknown primary. European journal of nuclear medicine and molecular imaging. 2010;37(3):635-44.

Cite this article as: Aktas B, Uygur ME, Soylemez MS, Kemah B, Bilgic B, Ceyran B, et al. Thyroid papillary carcinoma presenting with femoral neck metastasis: a case report. Int J Res Orthop 2016;2:2057. 